\title{
Avaliação da precipitação efetiva de um fragmento de Mata Atlântica em diferentes estágios de regeneração no município de Viçosa, MG
}

(doi:10.4136/ambi-agua.21)

\section{Rafael Figueiredo Alves'; Herly Carlos Teixeira Dias'; José Carlos de Oliveira Júnior²; Franklin Nicolai Mota Garcia ${ }^{1}$}

${ }^{1}$ Universidade Federal de Viçosa

${ }^{2}$ Plantar SA

E-mail: rafaelufv@hotmail.com; herly@ufv.br; jose-oliveira@plantar.com.br; fnmgarcia@yahoo.com.br

\section{RESUMO}

O presente trabalho teve por objetivo avaliar a precipitação efetiva de um fragmento do bioma Mata Atlântica composto por floresta estacional semidecidual em diferentes estágios de regeneração no município de Viçosa, MG, no período de novembro de 2005 a outubro de 2006. Foram demarcadas quatro parcelas experimentais, sendo três em uma área de estágio de regeneração inicial e uma em estágio de regeneração avançado. Durante o estudo foram efetuadas 24 coletas de precipitação a céu aberto, precipitação interna e escoamento pelo tronco, constituídas de um ou mais eventos de chuva. A precipitação média total do período estudado foi de $997 \mathrm{~mm}$. A precipitação efetiva na área em que o estágio de regeneração se encontra mais avançado, com área basal igual a $3,28 \mathrm{~m}^{2}$, foi de $813,90 \mathrm{~mm}$ o que correspondeu a $81,63 \%$ da precipitação a céu aberto. Na área em que o estágio de regeneração se encontra inicial, com área basal igual a $1,22 \mathrm{~m}^{2}$, a precipitação efetiva foi de $792,46 \mathrm{~mm}$ o que correspondeu a $79,43 \%$ da precipitação a céu aberto. A interceptação pelas copas resultou em $18,37 \%$ e $20,57 \%$ para as áreas de regeneração avançada e inicial, respectivamente. Os resultados analisados estatisticamente pelos testes $t$ e teste $f$, não apresentaram diferença significativa.ao nível de $5 \%$ de probabilidade.

Palavras-chave: Precipitação efetiva; mata atlântica; hidrologia florestal.

\section{Evaluation of net precipitation in a fragment of Mata Atlântica in different regeneration stages in the municipal district of Viçosa, MG.}

\section{ABSTRACT}

The goal of this present work was to evaluate the net precipitation in a fragment of the Mata Atlântica biome compound of semideciduous seasonal forest in different regeneration stages in Viçosa, MG, from November of 2005 to October of 2006. It was demarcated four experimental parcels, which three of them were allocated into an initial regeneration area and one into an advanced regeneration area. Gross precipitation, net precipitation and steamflow were measured in 24 storm events, constituted of one or more storm events. The mean precipitation during the studied period was $997 \mathrm{~mm}$. The net precipitation on higher advanced regeneration area that has a basal area of $3.28 \mathrm{~m}^{2}$, was $813.90 \mathrm{~mm}$ which corresponded to $81.63 \%$ of gross precipitation. The initial regeneration area, that has a basal area of $1.22 \mathrm{~m}^{2}$, was $792.46 \mathrm{~mm}$ which corresponded to $79.43 \%$ of gross precipitation. The canopy interception was $18.37 \%$ e $20.57 \%$, to advanced regeneration area and initial regeneration areas, respectively. The results were statistically evaluated by t-test and f-test, and showed no significant difference on $5 \%$ of probability.

Keywords: Net precipitation; mata atlântica; forest hydrology. 


\section{INTRODUÇÃO}

Em sua origem, a Mata Atlântica ocupava 15\% do território brasileiro e era distribuída por 17 estados desde o Rio Grande do Norte até o Rio Grande do Sul. Ela era a segunda maior floresta tropical da América do Sul, atrás somente da Floresta Amazônica. Depois de cinco séculos de devastação, porém, restam, atualmente, apenas $7,3 \%$ da área original desse bioma conhecido como uma das florestas de maior diversidade do mundo. O processo de devastação continua colocando em risco várias espécies que só são encontradas neste local. Em Minas Gerais a floresta secundária substituiu, praticamente, todas as florestas primárias existentes, restando apenas pequenas manchas remanescentes, que correspondem a menos de $2 \%$ do território mineiro (Dalben, 2006).

Segundo Castro et al. (1983) a cobertura florestal atua no ciclo hidrológico provocando um retardamento e redução da movimentação da água em direção aos cursos de água, por meio de processos de interceptação, infiltração, absorção, transpiração e percolação.

A precipitação pluvial é definida em hidrologia como toda água proveniente da atmosfera que atinge a superfície terrestre. Devido a sua capacidade de produzir escoamento superficial, a chuva é o tipo de precipitação mais importante para hidrologia florestal (Bertoni; Tucci, 2001).

Em florestas naturais ou plantadas, a quantidade de água de chuva que atinge a serrapilheira é denominada precipitação efetiva que é dada pela precipitação interna e escoamento pelo tronco (Lima, 1975).

A precipitação interna é a chuva que atinge o piso florestal, incluindo gotas que passam diretamente pelas aberturas existentes entre as copas e gotas que respingam do dossel. A fração da chuva que é retida temporariamente pelas copas juntamente com aquela que atinge diretamente os troncos, e que posteriormente escoam pelo tronco das árvores, chegando ao solo, é denominado escoamento pelo tronco. A soma da precipitação interna e escoamento pelo tronco são responsáveis pela água do solo (Arcova et al., 2003).

A precipitação efetiva pode variar em função de alguns fatores tais como: área basal, tipo de espécie, diâmetro das árvores, quantidade de espécies, densidade das árvores, além da freqüência e intensidade de chuvas. De modo que a área basal dos indivíduos pode levar a resultados mais consistentes quando comparados a precipitação efetiva da área.

Diante disto, este trabalho teve por objetivo avaliar a precipitação efetiva de um fragmento do bioma Mata Atlântica composto por formação florestal estacional semidecidual em diferentes estágios de regeneração no município de Viçosa, $\mathrm{MG}$, no período de novembro de 2005 a outubro de 2006.

\section{MATERIAIS E MÉTODOS}

\subsection{Características gerais da área de estudo}

A Estação de treinamento, pesquisa e educação Ambiental Mata do Paraíso (Figural e Figura 2), pertencente à Universidade Federal de Viçosa, localiza-se no município de Viçosa que por sua vez esta localizado ao norte da Zona da Mata do Estado de Minas Gerais, a 229 $\mathrm{Km}$ da capital Belo Horizonte. Situado entre as latitudes de $20^{\circ} 41^{\prime} 20^{\prime \prime} \mathrm{S}$ a $20^{\circ} 49^{\prime} 35^{\prime}$ 'S e entre as longitudes de 42 49' 36' 'WGr a 42 54' 27' 'WGr (Oliveira Jr., 2006). A uma altitude média de 650 metros, o município abrange uma área de $300,15 \mathrm{Km}^{2}$. A Mata do paraíso situase a aproximadamente $6 \mathrm{Km}$ da Universidade Federal de Viçosa e possui uma área de 194 hectares. 


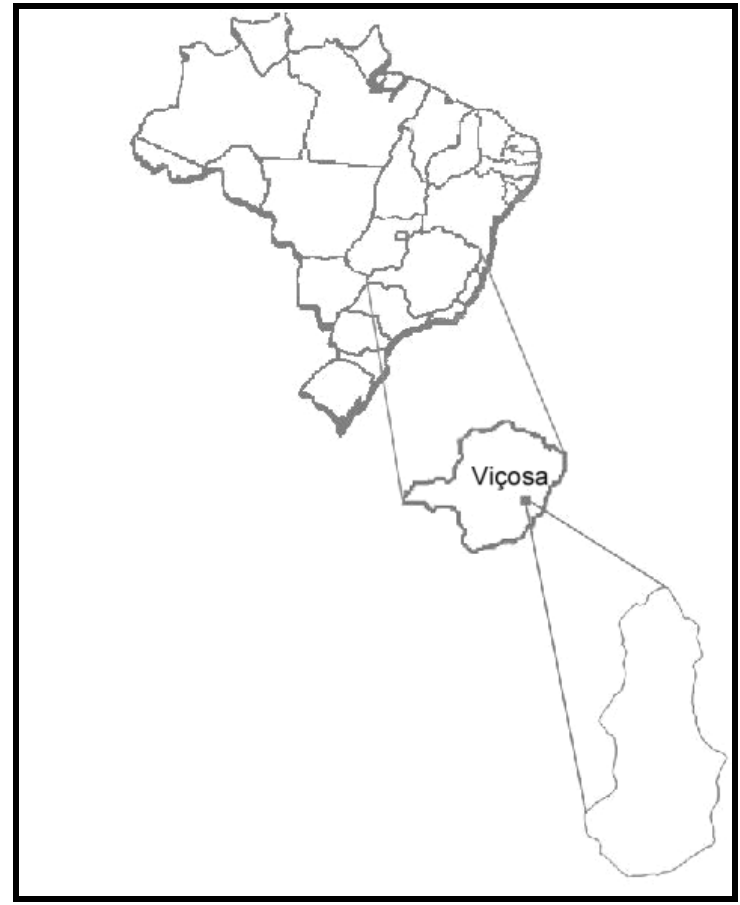

Figura 1. Localização geográfica da Estação de treinamento, pesquisa e educação Ambiental, Mata do Paraíso, Viçosa, MG.

Fonte: Oliveira Jr. (2006).

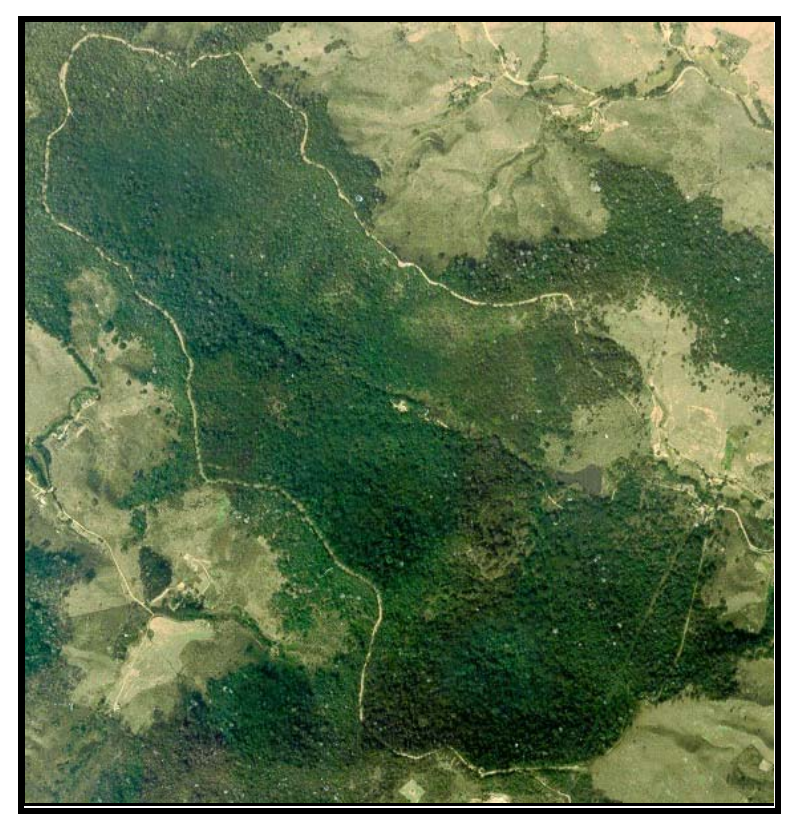

Figura 2. Localização geográfica da Estação de treinamento, pesquisa e educação Ambiental, Mata do Paraíso, Viçosa, MG.

Fonte: Oliveira Jr. (2006).

De acordo com a classificação de Köppen, o tipo climático de Viçosa é Cwa, descrito como:

"C" - clima temperado quente: sendo que a temperatura média do mês mais frio entre $18^{\circ} \mathrm{e}-3 \mathrm{C}$, mesotérmico. 
“w” - a época mais seca coincide com o inverno no hemisfério correspondente, comportando pelo menos um mês com precipitação, em média inferior a $60 \mathrm{~mm}$. A razão entre as precipitações mensais mínimas e máximas tem que ser inferior a 1/10.

"a" - a temperatura média do mês mais quente é superior a $22^{\circ} \mathrm{C}$.

A média das temperaturas máximas é de $26,1^{\circ} \mathrm{C}$ e a das mínimas é de $14,0{ }^{\circ} \mathrm{C}$, a umidade relativa média é elevada em todos os meses, com uma média anual de $80 \%$, a precipitação média observada é de $1220,0 \mathrm{~mm}$ por ano.

Em grandes áreas da Zona da Mata do Estado de Minas Gerais, incluindo o município de Viçosa e a Mata do Paraíso, a paisagem se divide em encostas, terraços, leito maior e leito menor. O leito menor é compreendido pelos cursos d'água. O leito maior refere-se às áreas da paisagem que são inundadas periodicamente, apresentando solos jovens devido a constante deposição de materiais feita durante o período de inundação. Os terraços são áreas que não são inundadas, com grande concentração de atividades humanas, urbanas e agrícolas, possuindo solos um pouco mais velhos que os solos do leito maior. As encostas são representadas por áreas de relevo acidentado, apresentando solos mais velhos da paisagem (Resende, 1971).

Os solos da Mata do Paraíso são classificados como Latossolo Varmelho-Amarelo distrófico nas áreas com perfis convexos, Câmbicos nos topos das elevações em função da existência de horizonte B de pequena espessura, Argilossolos nas áreas de perfis côncavos e nos terraços e Hidromórficos aluviais no leito maior.

A bacia hidrográfica, onde se encontra a Mata do Paraíso, possui uma forma retangular, onde o maior comprimento é paralelo ao curso d'água principal (Castro, 1980).

\subsection{Precipitação a céu aberto (P)}

A média da precipitação a céu aberto foi obtida a partir de medições realizadas com dois pluviômetros, sendo um deles simples de PVC com área de captação igual a $167 \mathrm{~cm}^{2}$ e o outro, um pluviômetro digital. Esses dois foram instalados acima do dossel da floresta.

Para o cálculo da precipitação atmosférica no pluviômetro de PVC, utilizou - se a equação:

$$
P=\left(\frac{V}{A}\right) \times 10
$$

em que P é a precipitação atmosférica $(\mathrm{mm}), \mathrm{V}$ é o volume do pluviômetro $(\mathrm{ml})$ e A é a área de captação do pluviômetro $\left(167 \mathrm{~cm}^{2}\right)$.

\subsection{Precipitação interna (Pi)}

Para quantificar a precipitação interna foram demarcadas três parcelas de $20 \mathrm{~m}$ x $20 \mathrm{~m}$ sucessivas, espaçadas entre si por $10 \mathrm{~m}$, na área de regeneração inicial, e uma parcela de $20 \mathrm{~m}$ por $20 \mathrm{~m}$ na área de regeneração mais avançada. Em cada parcela foram instalados 25 coletores com área de captação igual a $83,6 \mathrm{~cm}^{2}$.

Para o cálculo da precipitação interna em cada parcela utilizou-se a equação:

$$
P i=\frac{\left(\sum\left(\frac{V}{A}\right) \times 10\right)}{25}
$$

em que Pi é a precipitação interna $(\mathrm{mm}), \mathrm{V}$ é o volume de cada pluviômetro (ml) e A é a área de captação de cada pluviômetro $\left(\mathrm{cm}^{2}\right)$. 


\subsection{Escoamento pelo tronco (Et)}

Para quantificar o escoamento pelo tronco foram demarcadas 3 sub-parcelas de $10 \mathrm{~m} \mathrm{x}$ $10 \mathrm{~m}$ das parcelas da precipitação interna, na área de regeneração inicial e uma na área de regeneração avançada Em cada sub-parcela foram adaptados coletores à base de poliuretano nos troncos das árvores com CAP $\geq 15 \mathrm{~cm}$.

Para o cálculo do escoamento pelo tronco utilizou-se a seguinte equação:

$$
E t=\sum\left(\frac{V}{A S}\right)
$$

em que Et é o escoamento pelo tronco (mm), V é o volume de cada coletor (L) e AS é a área da sub-parcela.

\subsection{Precipitação efetiva (Pe)}

A precipitação efetiva foi calculada pela soma da precipitação interna e do escoamento pelo tronco, de acordo com a seguinte equação:

$$
P e=P i+E t
$$

em que Pe é a precipitação efetiva $(\mathrm{mm})$, Pi é a precipitação interna $(\mathrm{mm})$ e Et é o escoamento pelo tronco $(\mathrm{mm})$.

\subsection{Interceptação (Ic)}

A quantidade de água interceptada pela copa será obtida pela diferença entre a precipitação em aberto e a precipitação efetiva, de acordo com a equação abaixo:

$$
\text { Ic }=P-P e
$$

em que Ic é a perda por interceptação $(\mathrm{mm})$, P é a precipitação a céu aberto(mm) e Pe é a precipitação efetiva $(\mathrm{mm})$.

\section{7. Área Basal}

O diâmetro das árvores foi obtido a partir da medida do CAP (circunferência a altura do peito, $1,30 \mathrm{~cm}$ ) de todas as árvores com CAP $\geq 15 \mathrm{~cm}$, dentro de cada parcela de $20 \mathrm{~m} \times 20 \mathrm{~m}$. Primeiramente transforma-se o CAP em DAP pela seguinte equação:

$$
D A P=\frac{C A P}{\prod}
$$

em que DAP é o diâmetro a altura do peito $(1,30 \mathrm{~cm})$, e $\prod(3,1416)$

Para a totalização da área basal de cada parcela utilizou-se a seguinte equação:

$$
A b=\frac{\prod \times\left(D A P^{2}\right)}{40000}
$$

em que $\mathrm{Ab}$ é a área basal $\left(\mathrm{m}^{2}\right), \Pi(3,1416)$ e DAP é o diâmetro a altura do peito $(1,30$ $\mathrm{cm})$.

\section{RESULTADOS E DISCUSSÃO}

\section{1. Área basal}

Nas áreas de regeneração avançada (RA) e regeneração inicial (RI) foram encontradas, respectivamente, as áreas basais de 3,28 e 1,22 $\mathrm{m}^{2}$. Isso vem a confirmar a diferença nestas duas áreas quanto ao estágio de regeneração (RA e RI). Observa-se que, na área de regeneração inicial a um maior número de árvores de menores diâmetros e uma maior densidade populacional, o que dificulta o deslocamento. Já na área de regeneração avançada, 
o número de árvores é reduzido, e o diâmetro das árvores é maior. Além disso, pode-se observar uma diferença das duas áreas quanto ao fechamento do dossel.

Feita a distribuição por classe diamétrica podemos observar na Figura 3, que são poucos os indivíduos representados pelo centro de classe $2,5 \mathrm{~cm}$, na área de regeneração mais avançada, isto seria um estoque de regeneração presente na área, a partir do centro de classe $52,5 \mathrm{~cm}$ só foram encontrados indivíduos na área de regeneração mais avançada, mostrando que esta área esta mesmo a frente quanto ao estágio de regeneração.

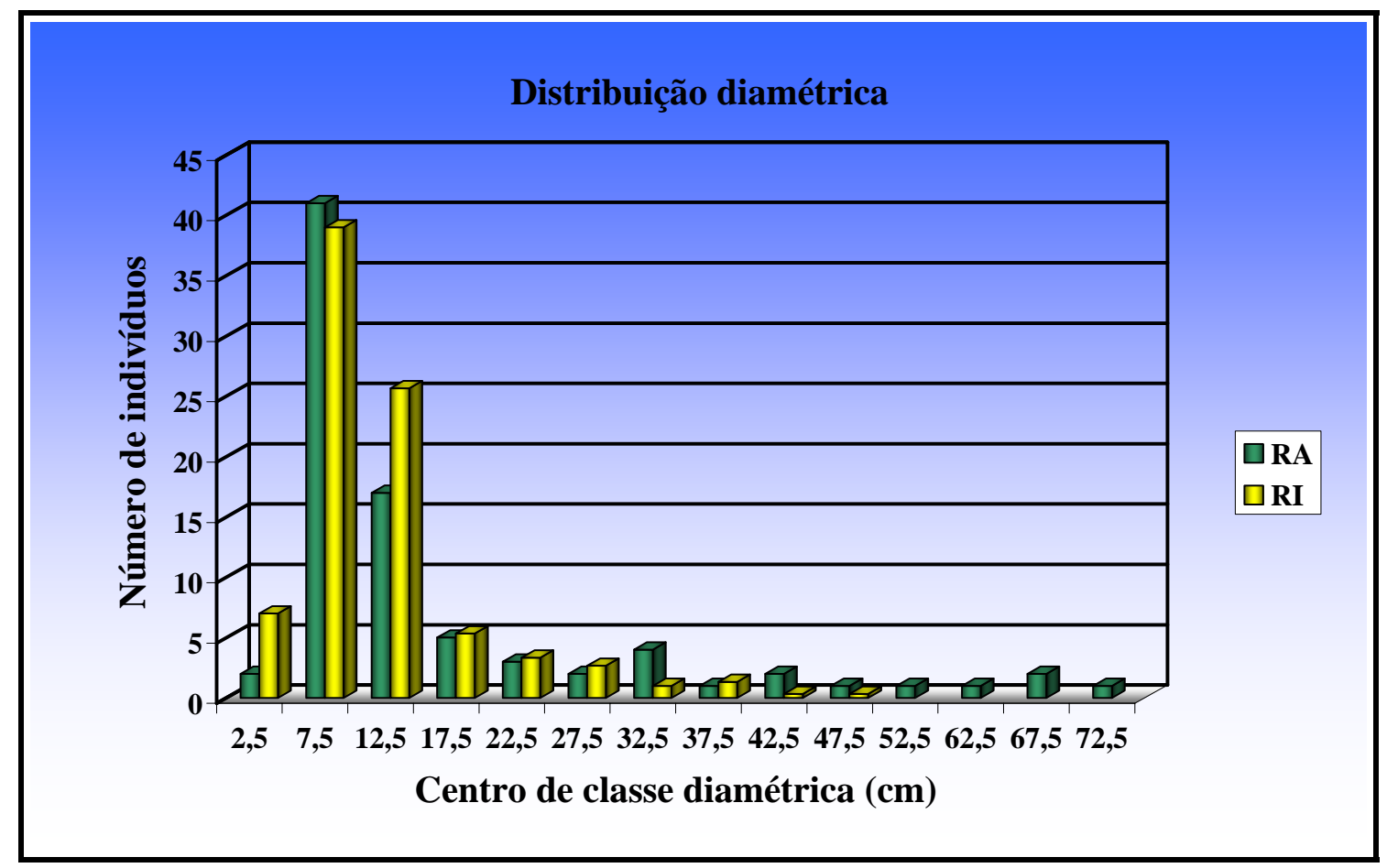

Figura 3. Distribuição por classe diamétrica na área de regeneração avançada (RA) e área de regeneração inicial (RI), Estação de treinamento, pesquisa e educação Ambiental, Mata do Paraíso, Viçosa, MG, novembro 2005 a outubro 2006.

\subsection{Precipitação efetiva}

A precipitação efetiva na área de regeneração mais avançada foi de $813,90 \mathrm{~mm}$ (Figura 4) o que correspondeu a 81,63\% (Figura 5) da precipitação total, já área em estágio de regeneração inicial a precipitação efetiva foi de 792,46 mm (Figura 4) o que correspondeu a $79,43 \%$ (Figura 5) da precipitação total para o período considerado. Os resultados foram analisados estatisticamente através dos testes $\mathrm{t}$ e $\mathrm{f}$ a $5 \%$ de probabilidade e não tiveram diferença significativa.

Oliveira Jr. (2006) realizando estudos na mesma área de regeneração inicial, encontrou valores de precipitação efetiva igual a $79,3 \%$ da precipitação em aberto, com valores de precipitação interna de $76,7 \%$ e o escoamento pelo tronco igual a $2,6 \%$, a perda por interceptação foi de $20,7 \%$. As diferenças nos resultados podem estar relacionados ao período hidrológico, estudado a intensidade das chuvas, a periodicidade na coleta de dados, entre outros.

Castro et al. (1983), citado por Oliveira Jr. (2006) realizando estudos na mesma mata, mas em locais diferentes encontraram precipitação efetiva igual a $87,6 \%$ da precipitação em aberto, com valores de precipitação interna e o escoamento pelo tronco igual a 87,4\% e, 0,2\% respectivamente, e perda por interceptação igual a 12,4\%. As diferenças encontradas entre as duas avaliações podem ser devido à metodologia, à própria condução do experimento ou 

efetiva de um fragmento de Mata Atlântica em diferentes estágios de regeneração no município de Viçosa, MG. Ambi-Agua, Taubaté, v. 2, n. 1, p. 83-93, 2007. (doi:10.4136/ambi-agua.21)

ainda à amostragem, no entanto os resultados sugerem também o efeito do fechamento e ingresso de espécies ao dossel nesses mais de 20 anos de diferenças entre os dois trabalhos.

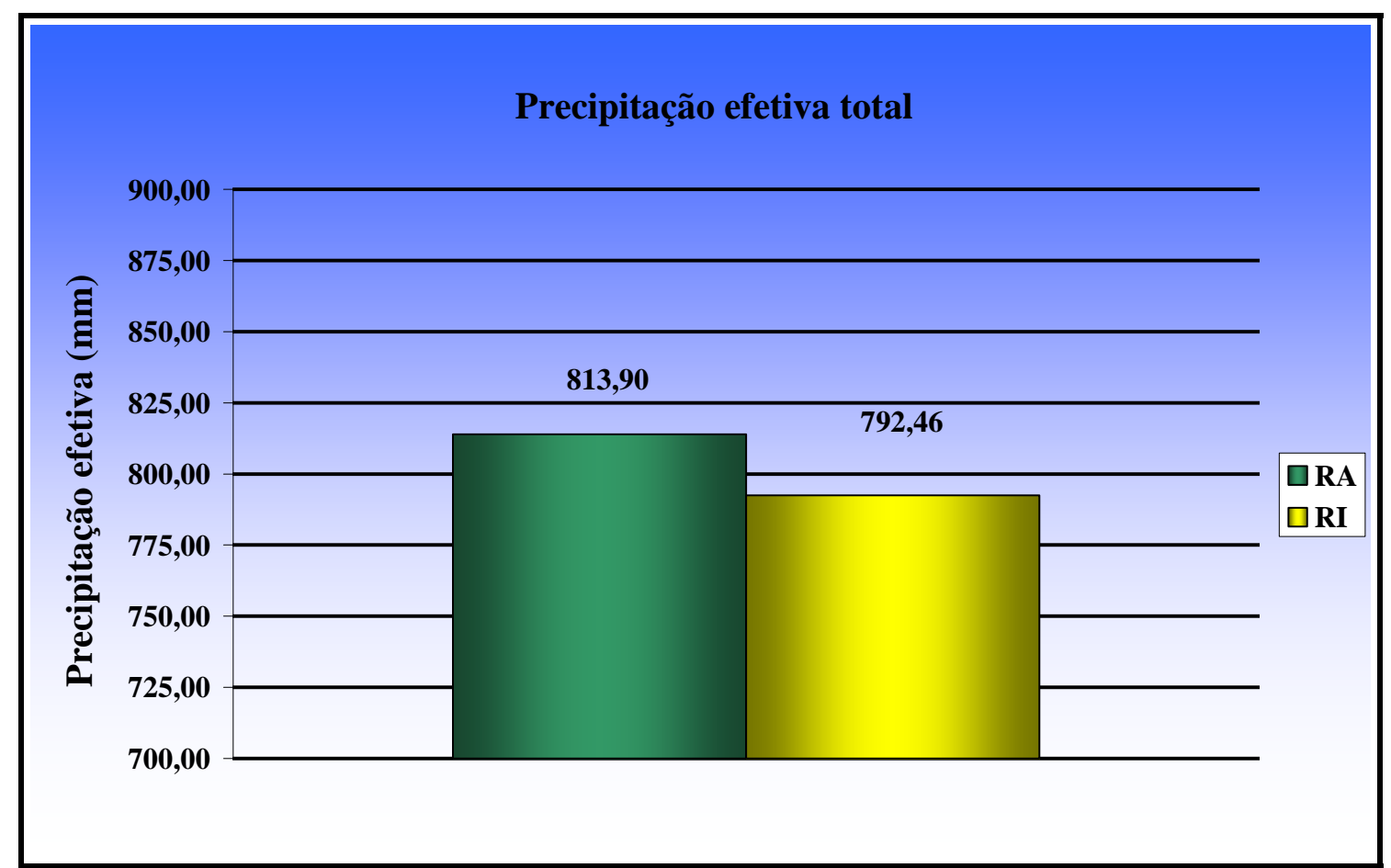

Figura 4. Precipitação efetiva total na área de regeneração avançada (RA) e área de regeneração inicial (RI), Estação de treinamento, pesquisa e educação Ambiental, Mata do Paraíso, Viçosa, MG, novembro 2005 a outubro 2006.

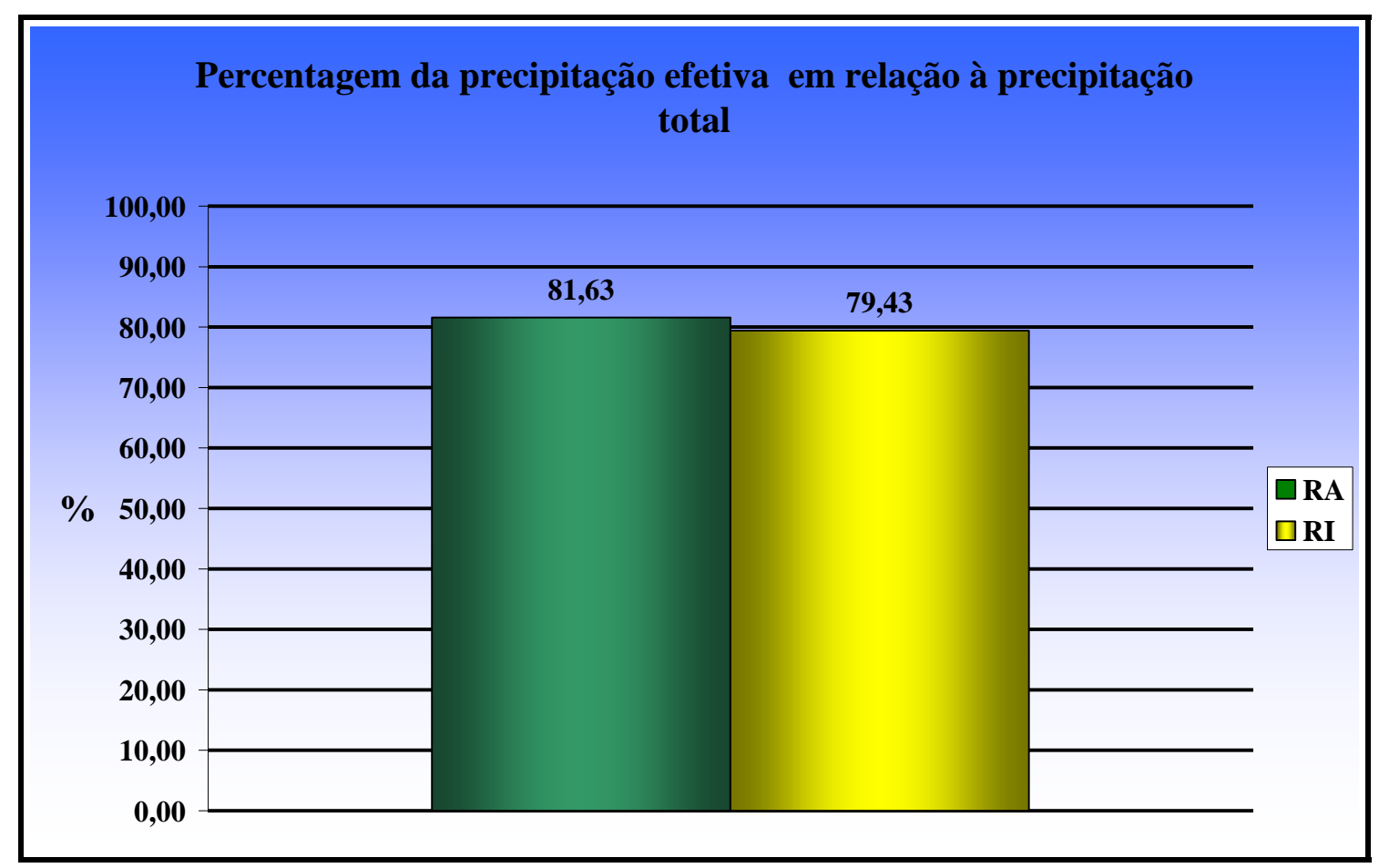

Figura 5. Precipitação efetiva em relação à precipitação total, em valores percentuais, na área de regeneração avançada (RA) e na área de regeneração inicial (RI), Estação de treinamento, pesquisa e educação Ambiental, Mata do Paraíso, Viçosa, MG, novembro 2005 a outubro 2006. 


\subsection{Precipitação interna}

$O$ valor da precipitação interna nas duas áreas em termos absolutos e em termos percentuais mostrados nas Figuras 6 e 7 respectivamente, na regeneração avançada este valor foi de $806,18 \mathrm{~mm}$ correspondendo a $80,86 \%$ da precipitação total, na área de regeneração inicial este valor foi de $788,69 \mathrm{~mm}$, o que correspondeu a $79,05 \%$ da precipitação total. Os resultados foram analisados estatisticamente através dos testes t e f a $5 \%$ de probabilidade e não tiveram diferença significativa.

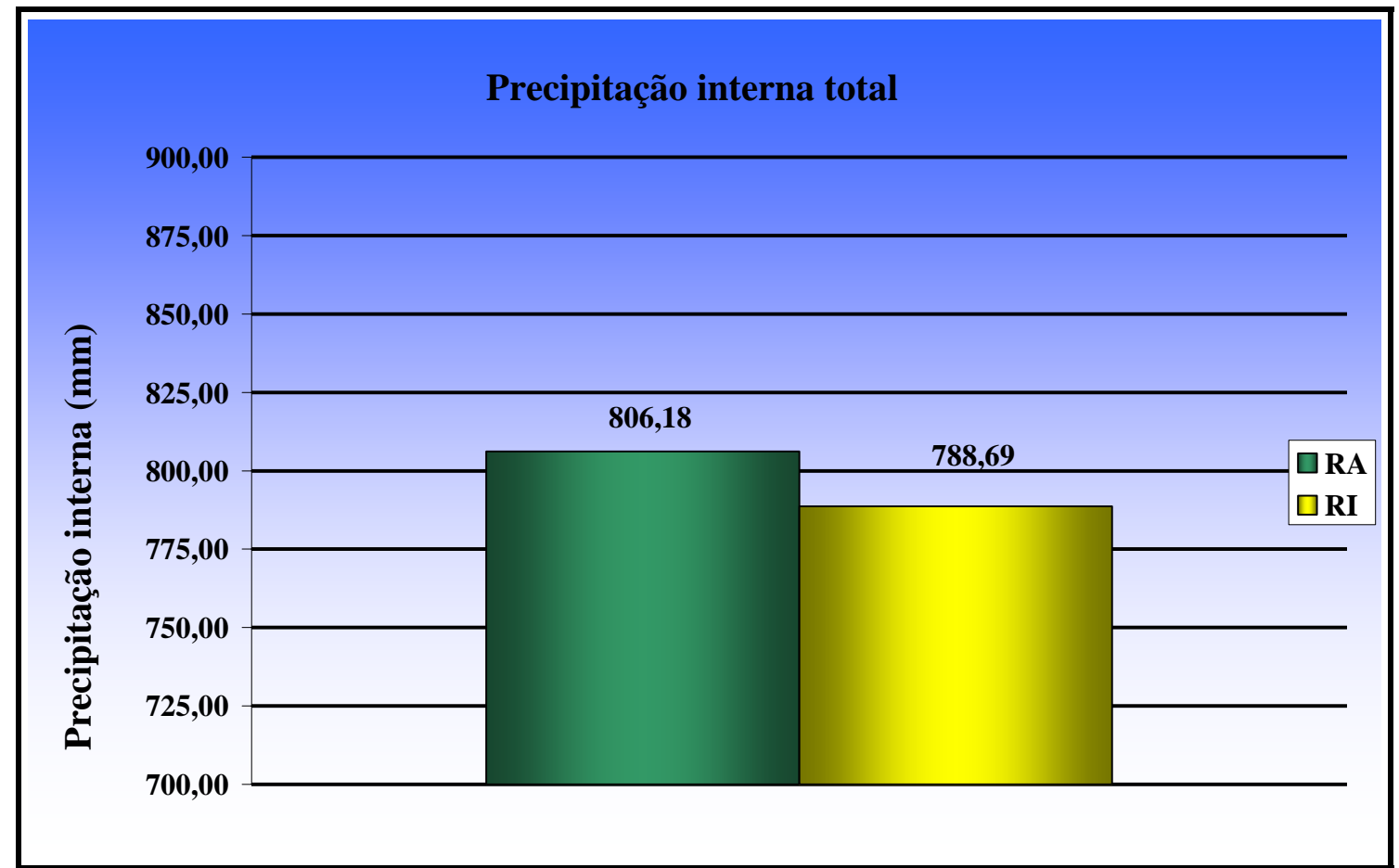

Figura 6. Precipitação interna total $(\mathrm{mm})$ nas áreas de regeneração avançada (RA), regeneração inicial (RI), Estação de treinamento, pesquisa e educação Ambiental, Mata do Paraíso, Viçosa, MG, novembro 2005 a outubro 2006.

Ferreira et al. (2005). Em floresta de terra firme submetida à extração seletiva de madeira na Amazônia Central encontrou valores de precipitação interna de 86,9 a 92,9\%, já na floresta intocada (controle) os valores foram de 74,2 a $87,1 \%$, essas alterações não foram significativas em termos estatísticos, mas influenciaram sensivelmente a quantidade de chuva nas áreas, levando a uma redução de chuva na área submetida ao manejo.

\subsection{Escoamento pelo tronco}

O Escoamento pelo tronco total encontrado para o período, foi de 7,72 $\mathrm{mm}$ na área de regeneração avançada (Figura 8), o que representa $0,77 \%$ da precipitação atmosférica total (Figura 9), já na área de regeneração inicial (RI) este valor foi de 3,77 mm (Figura 8), representando $0,38 \%$ da precipitação total atmosférica (Figura 9).

Os resultados foram analisados estatisticamente através dos testes $\mathrm{t}$ e $\mathrm{f}$ a $5 \%$ de probabilidade e não tiveram diferença significativa. Apesar do escoamento pelo tronco corresponder a um pequeno percentual da precipitação total, alguns autores consideram o volume escoado pelo tronco como um mecanismo de auto-abastecimento resultante da distribuição localizada e significante ao redor dos troncos, principalmente durante o período seco (Price, 1982; Huber; Oyarzún, 1983 citados por Lima; Leopoldo, 2000). O auto- 

efetiva de um fragmento de Mata Atlântica em diferentes estágios de regeneração no município de Viçosa, MG. Ambi-Agua, Taubaté, v. 2, n. 1, p. 83-93, 2007. (doi:10.4136/ambi-agua.21)

abastecimento exerce efeito sobre a qualidade da água que entra no solo (Johnson, 1990). O volume de água recebido nas proximidades dos troncos chegam a ser cinco vezes superior aquele recebido por áreas mais distantes (Navar; Bryan, 1990).

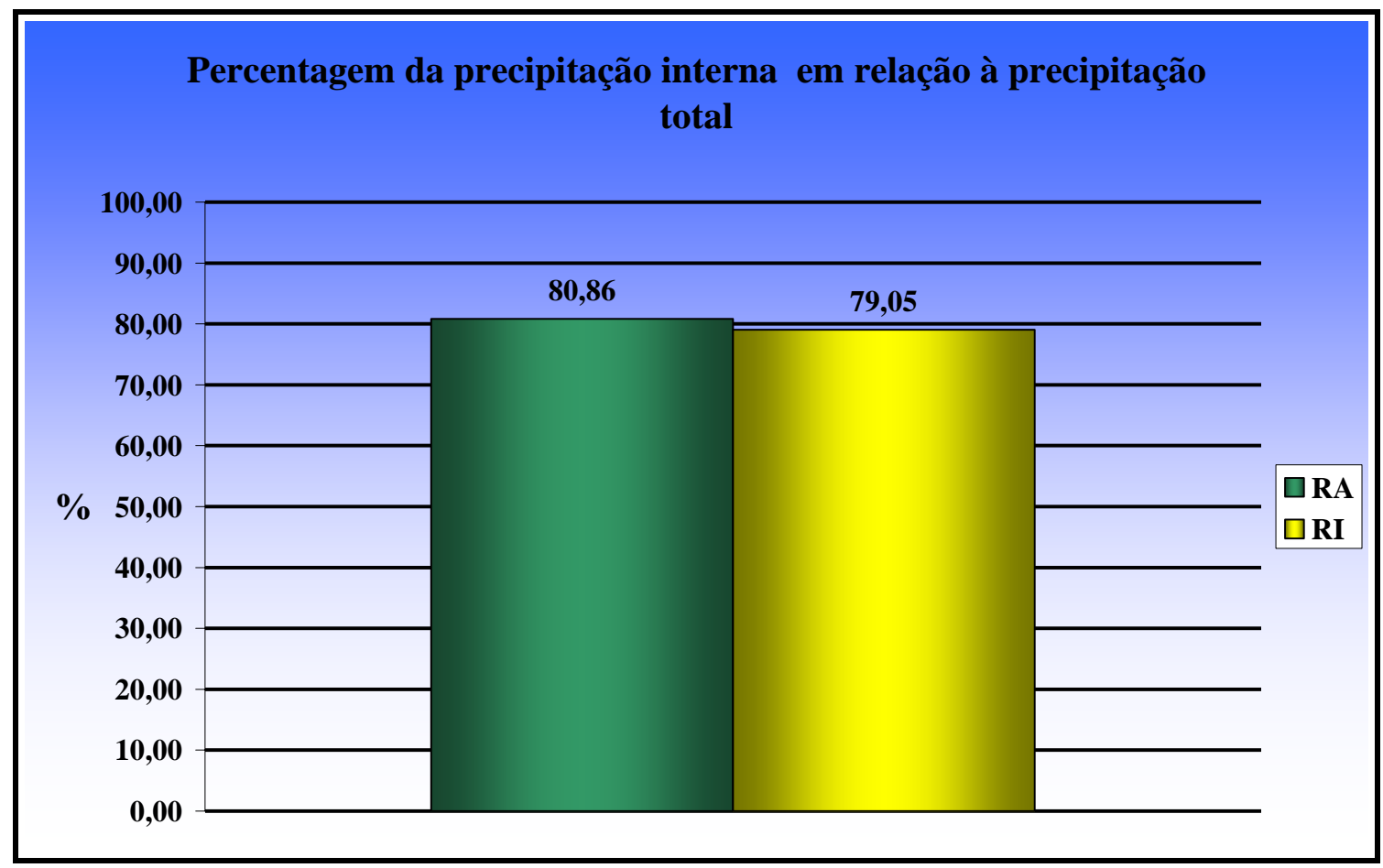

Figura 7. Precipitação interna em relação à precipitação total, nas áreas de regeneração avançada (RA), regeneração inicial (RI), Estação de treinamento, pesquisa e educação Ambiental, Mata do Paraíso, Viçosa, MG, novembro 2005 a outubro 2006.

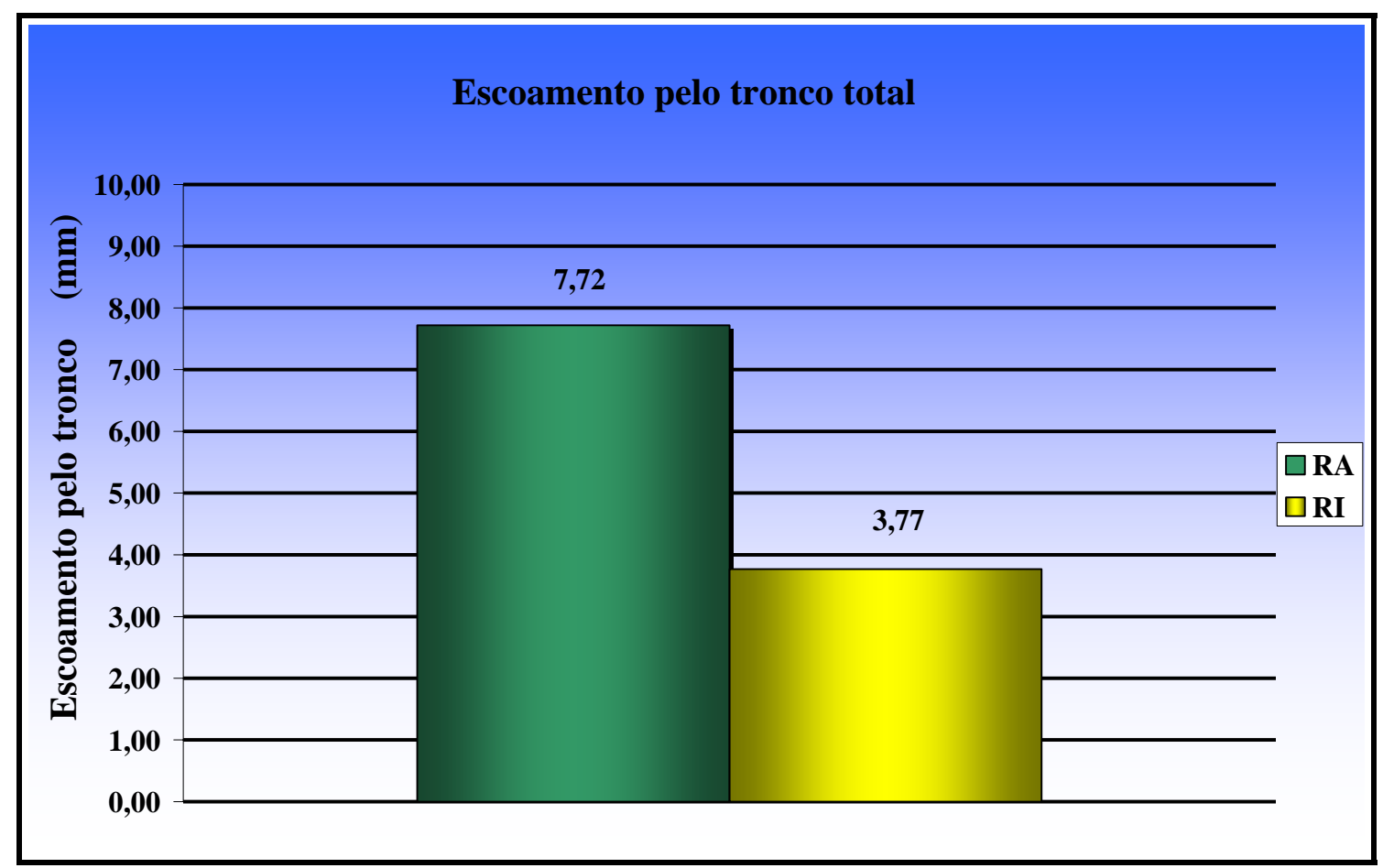

Figura 8. Escoamento pelo tronco total do período, em valores absolutos (mm), na área de regeneração avançada (RA) e na área de regeneração inicial (RI), Estação de treinamento, pesquisa e educação Ambiental, Mata do Paraíso, Viçosa, MG, novembro 2005 a outubro 2006. 


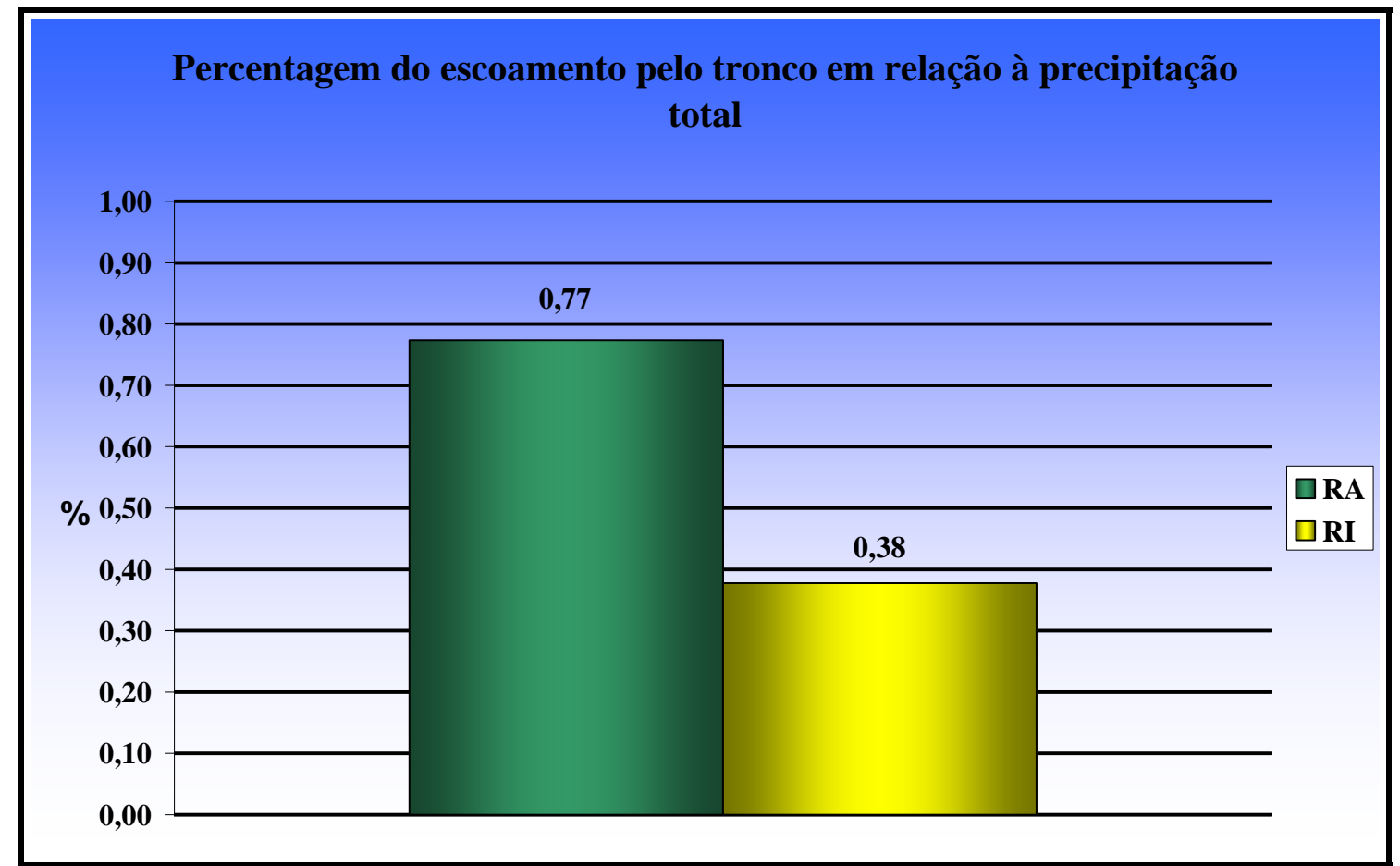

Figura 9. Percentagem do escoamento pelo tronco em relação à precipitação total nas áreas de regeneração avançada (RA) e regeneração inicial (RI), Estação de treinamento, pesquisa e educação Ambiental, Mata do Paraíso, Viçosa, MG, novembro 2005 a outubro 2006.

\section{CONCLUSÕES}

Com base nos resultados apresentados, podemos concluir que, estatisticamente não à diferença entre as áreas de regeneração inicial e avançada quanto à precipitação efetiva no período estudado. Além disso, a variável que mais contribui para a precipitação efetiva é a precipitação interna, ou seja, a água que passa entre o dossel da floresta ou que respinga da copa das árvores. Apesar da pequena contribuição do escoamento pelo tronco, este é de grande importância para a floresta como um todo. Foi comprovada a diferença nos estágios de regeneração pela área basal e distribuição diamétrica encontrada em cada área.

\section{REFERÊNCIAS}

ARCOVA, F. C. S.; CICCO, V.; ROCHA, P. A. B. Precipitação efetiva e interceptação das chuvas por floresta de mata atlântica em uma microbacia experimental em Cunha - SP. Revista Árvore, Viçosa, v. 27, n. 2, p. 257-262, 2003.

BERTONI, J. C.; TUCCI, C. E. M. Precipitação. In. TUCCI, C. E. M.(Org.) Hidrologia: ciência e aplicação. 2.ed. Porto Alegre: Universidade Federal do Rio Grande do Sul, 2001. p.177-242.

CASTRO, P. S. Influência da cobertura florestal na qualidade da água em duas bacias hidrogáficas na região de Viçosa, MG. 1980. 107p. Dissertação (Mestrado em Ciências Florestais) - Escola Superior de Agricultura "Luiz de Queiroz", Piracicaba, 1990. 
CASTRO, P. S.; VALENTE, O. F.; COELHO, D. T.; RAMALHO, R. S. Interceptação da chuva por mata natural secundária na região de Viçosa - MG. Revista Árvore, Viçosa, v. 7, n. 1, p. 76-89, 1983.

DALBEN, S. Mata atlântica: projeto promove educação ambiental e contribui para preservação desse ecossistema. Minas faz Ciência, Belo Horizonte, v. 27, n. 1, p. 24$25,2006$.

FERREIRA, S. J. F.; LUIZÃO, F. J.; DALLAROSA, R. L. G. Precipitação interna e interceptação da chuva em floresta de terra firme submetida à extração seletiva de madeira na Amazônia Central. ACTA Amazônica, Manaus, v. 35, n. 1, p. 55-62, 2005.

JOHNSSON, R. G. The interception, throughfall and stemflow in a forest in Highland Scotland and the comparison with other upland forests in the U.K. Journal of Hydrology, Amsterdam, v. 118, p. 281-287, 1990.

LIMA, P. R. A.; LEOPOLDO, P. L. Quantificação de componentes hidrológico de uma mata ciliar, através do modelo de balanço de massas. Revista Árvore, Viçosa, v. 24, n. 3, p. 241-252, 2000.

LIMA, W. P. Estudos de alguns aspectos quantitativos e qualitativos do balanço em plantações de eucaliptos e pinus. 1975. 111f. Tese (Doutorado em Ciência Florestal) Escola Superior de Agricultura "Luiz de Queiroz", Piracicaba, 1975.

NÁVAR, J.; BRYAN, R. Interception loss and rainfall redistriution by tree semi-arid growing shrubs in northeastern México. Journal of Hydrology, Amsterdam, v. 115, p. 51-63, 1990.

OLIVEIRA JR., J. C. Precipitação efetiva em floresta estacional semidecidual na Reserva Mata do Paraíso. 2006. 72f. Dissertação (Mestrado em Ciências Florestais) Universidade Federal de Viçosa, Viçosa, 2006.

RESENDE, S. B. Estudo de Crono-Toposequência em Viçosa, MG. 1971. 71f. Dissertação (Mestrado em Solos) - Universidade Federal de Viçosa, Viçosa, 1971. 